\title{
Bioactive effects of citrus flavonoids and role in the prevention of atherosclerosis and cancer
}

\author{
Marco Giammanco, ${ }^{1}$ Fulvio Plescia, ${ }^{2}$ Manfredi M. Giammanco, ${ }^{3}$ Gaetano Leto, ${ }^{4}$ Carla Gentile \\ ${ }^{1}$ Department of Surgical, Oncological and Oral Sciences, University of Palermo; ${ }^{2}$ Department of Health Promotion \\ Sciences Maternal and Infantile Care, Internal Medicine and Medical Specialties “Giuseppe D'Alessandro”, University \\ of Palermo; ${ }^{3}$ Medical School, University of Palermo; ${ }^{4}$ Laboratory of Experimental Pharmacology, Department of \\ Health Sciences, University of Palermo, Palermo; ${ }^{5}$ University of Palermo, Department of Biological, Chemical and \\ Pharmaceutical Sciences and Technologies, Section of Cellular Biology, Palermo, Italy
}

\begin{abstract}
Citrus fruits are the main fruits of the Mediterranean diet and have been long recognized for their beneficial effects on human health. Observational studies have shown a significant association between dietary flavonoid intake and reduced risk of cardiovascular and malignant diseases. The beneficial effects of citrus fruits on human health appear to be due to their high content in vitamins, minerals and fibers. In particular, the antioxidant and anti-inflammatory activities have been indicated as some of the mechanisms through which citrus fruits may thwart the development of chronic degenerative diseases such as atherosclerosis and cancer. This
\end{abstract}

Correspondence: Marco Giammanco, Department of Surgical, Oncological and Oral Sciences, University of Palermo, Via Liborio Giuffre 5, 90127 Palermo, Italy.

E-mail: marco.giammanco@unipa.it

Key words: Citrus flavonoids; antioxidant; atherosclerosis; cancer; human health; cardiovascular diseases; antioxidant activities; antiinflammatory activities.

Acknowledgments: Authors are supported by the University of Palermo, Italy.

Funding: Supported by University of Palermo.

Contributions: Conceptualization, MG; writing and editing, all the authors. All authors have read and agreed to the published version of the manuscript.

Conflicts of Interest: Authors declare no conflict of interest.

Received for publication: 5 December 2021.

Revision received: 8 January 2022.

Accepted for publication: 8 January 2022.

${ }^{\circ}$ Copyright: the Author(s), 2022

Licensee PAGEPress, Italy

Journal of Biological Research 2022; 95:10313

doi:10.4081/jbr.2022.10313

This article is distributed under the terms of the Creative Commons Attribution Noncommercial License (by-nc 4.0) which permits any noncommercial use, distribution, and reproduction in any medium, provided the original author(s) and source are credited. review would critically examine the results from numerous experimental and clinical studies carried out in order assess the contribute of citrus flavonoids to the prevention of chronic pathological conditions including atherosclerosis and cancer.

\section{Introduction}

Growing experimental and observational studies provide evidence that the beneficial effects exerted by foods on human health appears to be due to their content in vitamins, minerals, fiber and antioxidant nutraceutical components that provide functional characteristics to foods and account for their preventive effects on chronic-degenerative diseases. ${ }^{1}$ Several antioxidant phytochemicals that are present in fruits and vegetables, can modulate the metabolic functions and redox balance of human cells in order to maintain their integrity and tissue homeostasis to prevent the onset of chronic-degenerative diseases. ${ }^{2}$ Plants biodiversity is related to the presence of a wide range of different chemical compounds, including phythochemicals, many of which are endowed with important pharmacological properties and whose beneficial effects on human health are currently under extensive investigations. ${ }^{3}$ In this setting, numerous observational studies have highlighted the fact that an increased consumption of fruits and vegetables may protect humans against chronic degenerative diseases, such as cancer and atherosclerosis (Table 1). ${ }^{4-5}$ For instance, flavonoids are an heterogeneous group of substances largely present in plants which show to possess several pharmacological functions. ${ }^{6}$ These molecules protect plants from UV radiation and pathogens. ${ }^{7}$ Dietary flavonoids are important components of the human diet. ${ }^{6}$ These compounds are present in significant amount in a wide variety of foods including fruit, vegetables, nuts, cocoa, soy, coffee, tea, and wine. ${ }^{8}$ Epidemiological studies have shown a significant correlation between dietary flavonoid intake and decreased incidence of cardiovascular diseases, cancer, ${ }^{8,9}$ type 2 diabetes, ${ }^{10}$ neurodegenerative disorders, ${ }^{11}$ and osteoporosis. ${ }^{12}$ Although some observational studies failed to show significant correlation between total flavonoids intake and reduced risk of stroke, they reported a significant association between increased intake of citrus flavonone subclass from orange and grapefruit and reduced risk of ischemic stroke in women. ${ }^{13}$ This review would provide insight into the most recent findings and advances in understanding the cellular mechanisms underlying the preventive effects of citrus flavonoids on the onset of some chronic pathological conditions such as atherosclerosis and human tumors. 


\section{Classification and distribution of flavonoids}

Flavonoids are a heterogeneous group of substances widely present in many foods. Flavonoids are a subclass of calorie-free polyphenols. ${ }^{14}$ These molecules belong to a class of secondary plant metabolites showing a polyphenolic structure, which are widely present, in particular, in fruit, vegetables and which are endowed of various biological activities. ${ }^{15}$ The common chemical structure of flavonoids consists of two aromatic rings linked by three carbon atoms that form an oxygenated heterocycle (Figure 1). The differences in the chemical structure of each group of flavonoids are given by the different number and arrangement of the hydroxyl groups and by their degree of alkylation and glycosylation. These molecules can be detected as free aglycone form. However, they are often linked to glycosides. In this form these compounds are soluble in water. ${ }^{16}$ Flavonoids are endowed with antioxidant activity that account for their preventive effects on the onset of chronic diseases such as cancer, atherosclerosis and neurodegenerative diseases (Figure 2 and 3 ) ${ }^{15}$ In this setting, accumulating evidence has indicated that the presence of these substances into the daily diet can contribute to the beneficial effects on human health and to prevent on the onset of degenerative diseases. ${ }^{1}$ Flavonoids are the major water-soluble plants pigments which are involved in the production of the colors needed to attract pollinating insects. In particular, citrus peel and seeds are rich in phenolic compounds, being peels richer in flavonoids than seeds. ${ }^{17}$ The juices of bergamot, grapefruit and bitter orange are rich in naringin, neohesperidin and neoeriocitrin. While bergamot, orange, mandarin, and lemon juices has high contet of hesperidin, narirutin and didimin. ${ }^{18,19}$ Eriocitrin and hesperidin are contained in good quantities in lemon, while neoesperidin and naringin are found in bitter orange. Bergamot seeds are rich in glycosylated flavanones, naringin and neohesperidin. ${ }^{17,20}$ Naringin has been found in lemon peel and mandarin seeds. However it is not present in the juices of these fruits..$^{21}$ According to their molecular structures, flavonoids are divided into six major subtypes, which include fla-<smiles>Cc1cc(-c2cc(=O)c3c(O)cc(O)cc3oc2=O)cc(C)c1O</smiles><smiles>Cc1cc(C2(c3cc(O)cc4c3C(C)(C)C(O)(c3cc(C)c(O)c(C)c3)C(C)(O)C4O)CC(=O)c3c(O)cc(O)cc3O2)cc(C)c1O</smiles><smiles></smiles>

Figure 1. Structures of flavonoids.

Table 1. Citrus flavonoid and atherosclerosis.

\begin{tabular}{|c|c|c|c|}
\hline Phytochemical, Flavonoid, food & Experimental syst & Results & References \\
\hline Genistein, apigenin, biochanin A, naringin, quercetin & In vitro studies & Inhibit in vitro LDL oxidation & [49] \\
\hline $\begin{array}{l}\text { Hesperetin, m-hydroxycinnamic acid (m-HC), } \\
\text { 3,4-dihydroxyphenylpropionic acid (3,4-DHPP), } \\
\text { and 3-methoxy-4-hydroxycinnamic acid (ferulic acid) }\end{array}$ & Animal model & $\begin{array}{l}\text { Supplementation of hesperetin and its metabolites } \\
\text { significantly lowered the plasma total cholesterol and triglyceride }\end{array}$ & [52] \\
\hline Naringenin & Animal model & $\begin{array}{l}\text { Decreased the plasma fatty acid, } \\
\text { hepatic pro-inflammatory mediators, expression } \\
\text { of genes including tumor necrosis factor- } \alpha \text {, } \\
\text { interlukin-6, interleukin-1 } \beta \text {, inducible nitric oxide synthase } \\
\text { and matrix metalloproteinases (MMP-2, } 9 \text { ) }\end{array}$ & [53] \\
\hline Naringenin & Animal model & $\begin{array}{c}\text { Inhibition of 3-hydroxy-3-methylglutaryl } \\
\text { coenzyme A reductase and acyl coenzyme A: } \\
\text { cholesterol acyltransferase }\end{array}$ & {$[56]$} \\
\hline Naringin & Animal model & $\begin{array}{l}\text { Reduced plaque progression only in wild-type } \\
\text { mice fed the high-fat/high-cholesterol diet }\end{array}$ & [58] \\
\hline Orange juice & Clinical study & $\begin{array}{l}\text { Reduction in blood levels of total cholesterol, } \\
\text { LDL cholesterol, apo B and LDL / HDL ratio }\end{array}$ & [65] \\
\hline Glucosyl hesperidin (G-hesperidin) & Clinical study & Reduction in triglycerides in subjects with hyprtriglyceridemia & {$[68]$} \\
\hline Glucosyl hesperidin (G-hesperidin) & Clinical study & $\begin{array}{l}\text { Reduction in triglycerides in subjects with hyprtriglyceridemia } \\
\text { and reduction of small dense low-density lipoprotein }\end{array}$ & [69] \\
\hline Naringin & Clinical study & $\begin{array}{l}\text { Reduction of total plasma cholesterol and low density } \\
\text { lipoprotein cholesterol in hypercholesterolemic subjects }\end{array}$ & [70] \\
\hline Orange juice & Clinical study & Reduction diastolic blood pressure & [73] \\
\hline
\end{tabular}


vanols, flavanones, flavonols, isoflavones, flavones and anthocyanins, depending on the differences in their structures. ${ }^{22,23}$ More than 4000 varieties of flavonoids have been identified to date. ${ }^{24}$ Among the aglycone forms naringenin and hesperetin are considered the most important flavanones, while the glycoside forms includes neohesperidosides and rutinosides. ${ }^{25}$ The neohesperidosides, flavanones, naringin, neohesperidin and neoeriocitrin are constituted by a flavanone with neohesperidose. Rutinosides (flavanones, hesperidin, narirutin and didymin) have a disaccharidic residue such as rutinose. ${ }^{25}$

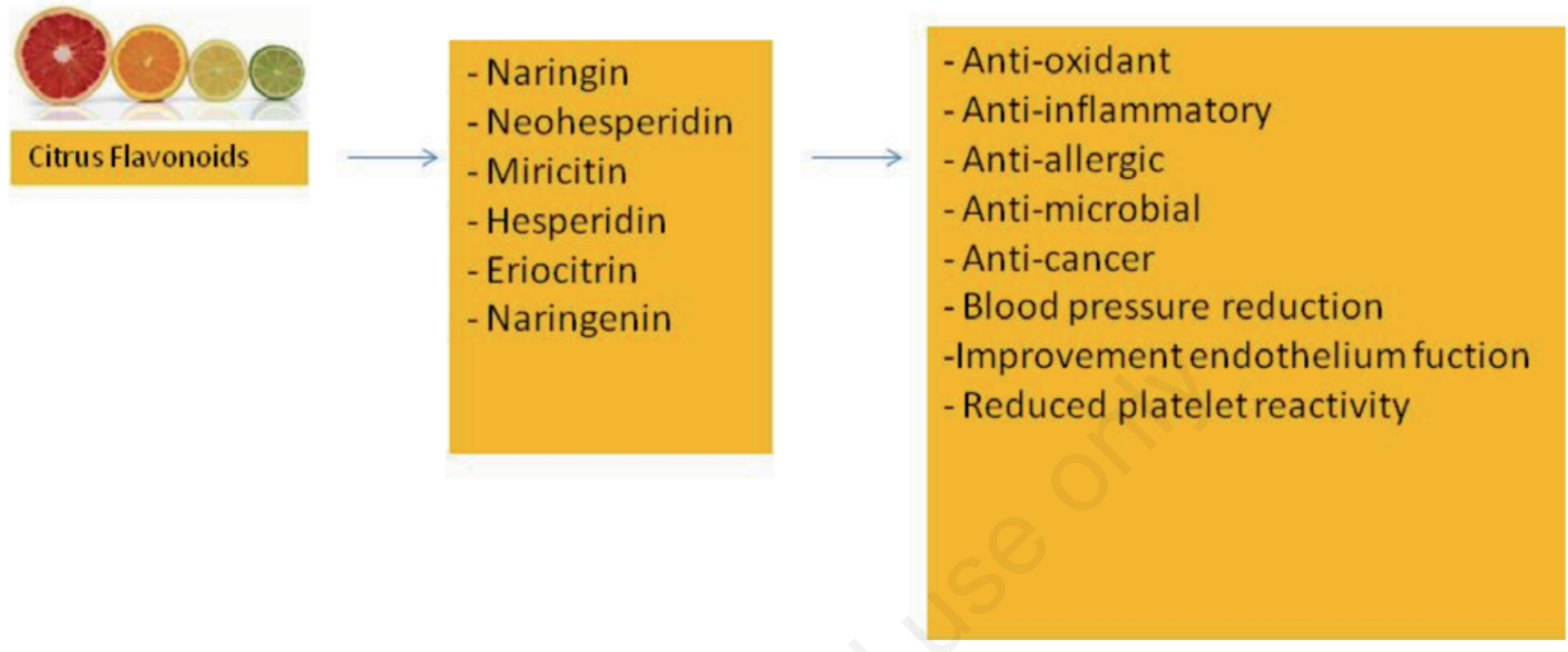

Figure 2. Effects of citrus flavonoids.

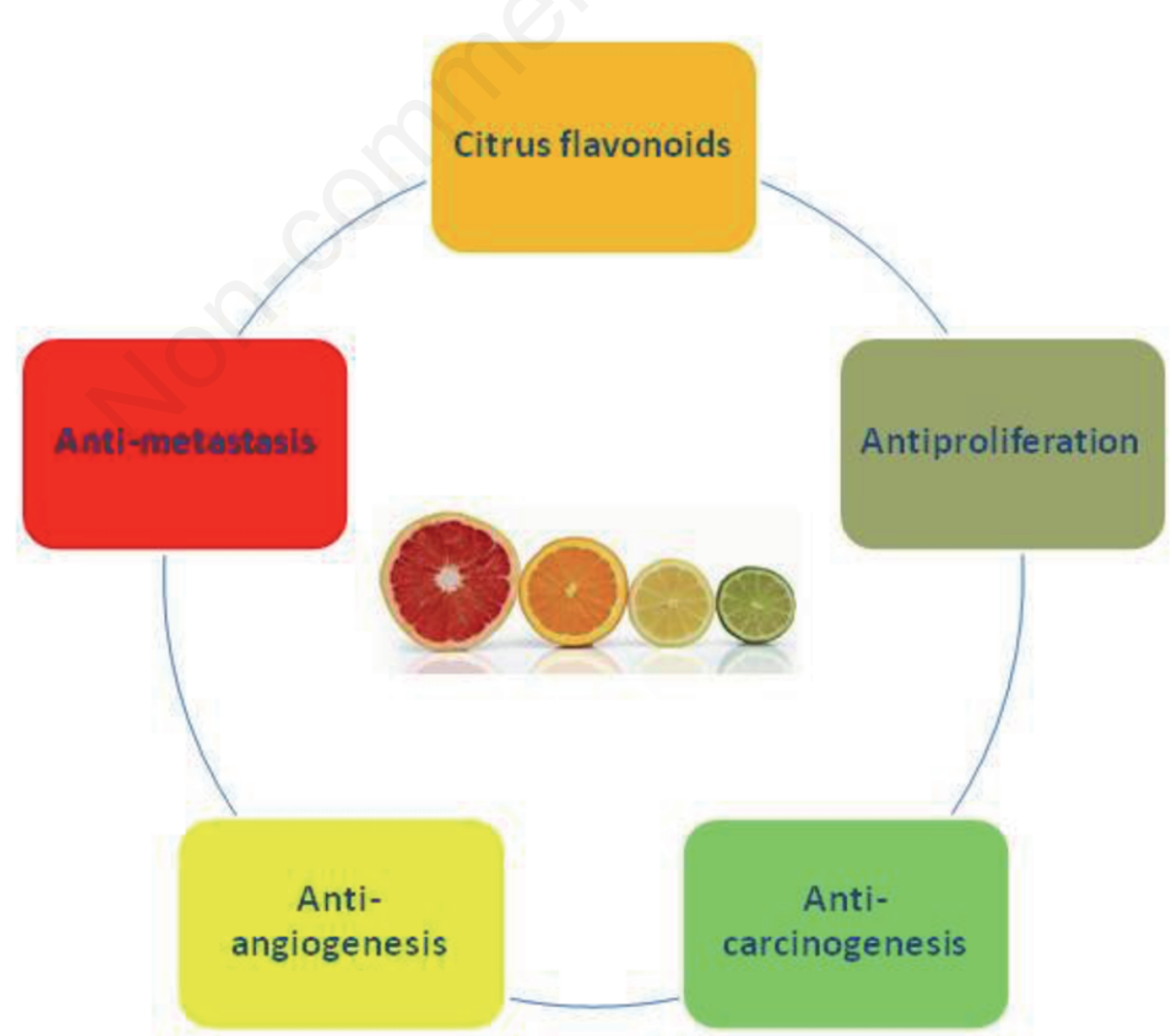

Figure 3. Anti-cancer effects of citrus flavonoids. 


\section{Bioavailability}

Flavonoid glycosides are hydrolized into their aglycone form by the intestinal microflora and then, in this form, can be absorbed. Flavonoids undergo extensive hepatic metabolism by hydroxilation or demethylation and then conjugated with glicuroinic acid or sulphates. The metabolism of flavonoids depends on hydroxylation which modifies their sensitivity to hydrolysis and to the cleavage of the heterocyclic ring by the bacterial flora ${ }^{8}$ Therefore, due to the intestinal flora, the metabolism of the different flavonoids can vary according to the specific chemical structure. ${ }^{26}$ The flavanone, hesperidin and naringin glycosides are both rutinosides linked to disaccarides ramnose and rutinose in position 7 . Consequently, they are not hydrolyzed by intestinal bacterial $\beta$-glucosidases but however the flavonoids are metabolized in the distal part of the small intestine and colon by the microflora. ${ }^{27}$ The 7 -glucoside forms of naringenin and hesperin are rapidly absorbed as they are hydrolyzed in the small intestine. ${ }^{27}$ Naringenin and esperperin are absorbed within minutes when administered orally, with a peak plasma concentration at approximately three hours. ${ }^{28}$ Flavonoids can accumulate in the body, in one study, naringin was administered to rats resulting in increased concentrations mainly in the liver, followed by spleen, heart, brain and kidneys. ${ }^{29}$

\section{Antioxidant activity}

Flavonoids show anti-oxidant effects against free radicals. ${ }^{30}$ The scavenger ability of these molecules has been suggested to be due to their hydrogen-donating capability so that a subsequent production of radicals can be delocalized on the flavonoid structure. ${ }^{31,32}$ The antioxidant potential of flavonoids is determined by the presence of glycosides and free hydroxyl groups or by the number and position of esterified hydroxyl groups. ${ }^{33}$ The concentration of flavonoids and several environmental factors influences the antioxidant activity. The common structural element is the configuration of the C-ring with the 3-hydroxyl group, which activates the double bond in position 2-3. Only when the concentration is lower than $100 \mu \mathrm{M}$ the presence of the hydroxyl groups in the ring $\mathrm{B}$ is important for the radical scavenger activity. ${ }^{34}$ Furthermore, $\mathrm{pH}$ has been also shown to affect the antioxidant activity of some polyphenols. ${ }^{35}$ The rate of flavonoids activity appears also to be related to their chemical structure. Flavonoids has been shown to be and are excellent scavengers of the hydroxyl radical. ${ }^{36}$ In this context Rapisarda et al. determined the antioxidant capacity of polyphenols, flavonoids, anthocyanins, hydroxycinnamic acids and ascorbic acid which were present in of the juice pigmented oranges of Moro, Sanguinella, Tarocco and Washington varieties. The juice from all these varieties showed an antioxidant activity, which appears correlated with the total amount of phenol and that is influenced by the pigmented component of anthocyanins. ${ }^{37,38}$ An in vitro study showed that quercetin and kaempferol are able to cross the erythrocyte membrane and increase antioxidant activity of erythrocyte by $15 \%$ and $13 \%$ respectively. ${ }^{39}$ These findings indicate that flavonoids are able to form stable complexes with erythrocytes and may influence intracellular redox homeostasis. Therefore, these observations support the hypothesis that polyphenols are able to protect erythrocytes from reactive oxygen species (ROS) induced cell damage. ${ }^{39}$ Other observational studies carried out to compare the activity of catalase in erythrocytes of smokers versus non-smokers, showed that the enzymatic activity of catalase was significantly lower in smokers than in non-smokers. Furthermore, these studies also reported that exposures of erythrocytes from smokers to quercetin at a concentration of $100 \mu \mathrm{M}$ resulted in an return of catalase levels to normal values. ${ }^{40}$

\section{Anti-inflammatory activity}

Many experimental studies have shown that flavonoids can inhibit the expression of enzymes or transcription factors that regulate the biological functions of signalling molecules involved in inflammation. ${ }^{40}$ The effects on the immune and inflammatory responses induced by flavonoids appear to be, in part, the result of the inhibition of the expression levels of enzymes such as proteinkinase $\mathrm{C}$, phosphodiesterase, phospholipase, lipoxygenase and cyclooxygenase, which regulate the synthesis of biological effectors responsible for the activation of endothelial cells and cells of the immune system involved in inflammation. ${ }^{40}$ Flavonoids has been also shown to inhibit enzymes such as aldose-reductase, xanthine-oxidase, phosphodiesterase, $\mathrm{Ca}^{(+2)}$-ATPase, lipoxygenase, and cyclooxygenase, which play a role in promoting the transduction and activation of cellular signals and to modulate the activation of cells involved in the immune response. ${ }^{41,42}$ In this setting, experimental in vivo studies have shown that hesperidin inhibited carrageenan-induced pleurisy and reduced yeast-induced hyperthermia in rats. ${ }^{43}$ Hesperidin, in particular, has been shown to exert inhibitory effects on Lipopolysaccharide (LPS) induced by the expression of cyclooxygenase-2, inducible nitric oxide synthase (iNOS), hyperproduction of prostaglandin E2 and nitric oxide (NO) ${ }^{44}$ On the other hand, nobiletin has been reported to selectively downregulate cyclooxygenase-2, and the gene expression of pro-inflammatory cytokines, by mechanisms resembling those of dexamethasone. ${ }^{45}$

\section{Prevention of atherosclerosis and cardiovascular diseases}

Citrus flavonoids have attracted particular attention due to their unique and effective therapeutic activity against various chronic diseases, in particular atherosclerosis (Table 1). ${ }^{46}$ Inflammation of the vessel wall and increased adhesion of mononuclear cells to the altered endothelium are the the first step of the atherosclerosis. In response to inflammation, Low-Density Liproteins (LDL) can penetrate the intima of the arterial wall and, following LDL-laden foam cells, can form atherosclerotic plaques. ${ }^{47,48}$ Citrus flavonoids, including naringin, have shown to exert inhibitory effects on the oxidation of LDL cholesterol. ${ }^{49}$ Citrus consumption has been associated with an assessmented of cardiovascular events, suggesting that citrus flavonoid intake may be cardioprotective. ${ }^{50}$

\section{Animal studies}

Numerous preclinical in vivo studies have reported positive effects of the intake of citrus fruits, derived from peels and seeds or molecules administered individually or in combination. For instance Kurosawa et al. investigated the hypocholesterolemic effects of citrus juices in mildly hypercholesterolemic rats in which high levels of LDL were obtained following the intake of high-fat diet. These studies showed that orange juice and grapefruit juice affected cholesterol metabolism. In particular, the administration to rats of a diet in which water was replaced with orange juice and $32 \%$ with grapefruit juice, induced an evident decrease of serum LDL cholesterol in $43 \%$ of the animals. ${ }^{51}$ Hesperetin was also noted to exert a hypolipidemic effect. In fact, in male rats fed a high cholesterol diet, the administration of this compound reduced the circulating level of triglycerides and cholesterol. ${ }^{52}$ Furthermore, Chtourou et al. reported that in Wistar rats fed with a 
high cholesterol diet, the administration of naringenin, resulted in a reduction of plasma lipids, liver lipids and liver fibrosis. These effects were associated with the decreased expression levels of matrix metalloproteinase and that of macrophage infiltration markers. ${ }^{53}$ Furthermore, studies carried out on hamsters fed with dietinduced hypercholesterolemia, showed that formulations containing citrus polymethoxylated flavones, mainly tangeretin or citrus flavanone glucosides, hesperidin and naringin, significantly reduced the circulating levels of the Very Low Density Lipoproteins (VLDL) and serum cholesterol. ${ }^{54}$ In addition, the administration to $\mathrm{db} / \mathrm{db}$ mice of cross-linked Citrus peel extract caused a decrease in fat liver and in plasma lipids. ${ }^{55}$ Other studies have shown that a dietary supplementation with naringenin reduced cholesterol plasma levels and those of triacylglycerol, in the liver of rats fed a high cholesterol diet. These effects resulted also associated with a decrease in 3-hydroxy-3-activity methylglutaryl-coenzyme A reductase (HMG-CoA) and Acyl-CoA: Cholesterol Acyltransferase (ACAT). ${ }^{56,57}$ Experimental studies on wild type mice fed a integrated diet high fat/cholesterol/highnaringin, reported significant anti-atherogenic effects, in particular, in the case of diet-induced atherosclerosis. ${ }^{58}$ On the other hand, rabbits fed high cholesterol diet showed that the integration of naringin and naringenin reduced the area of fat strips in the thoracic aorta. Interestingly, this effect was associated with reduced expression levels of adhesion of vascular cell adhesion molecule-1 (VCAM-1) and Monocyte Chemoattractant Protein-1 (MCP-1) as compared to the control group. ${ }^{59,60} \mathrm{On}$ the other hand, low-density lipoprotein receptor-null mice (Ldlr-/-mice) fed the western diet and supplemented with 3\% naringenin diet showed a reduction in the infiltration of monocyte/macrophage antibody-2 (MOMA-2) positive lesions and collagen deposition. These findings are suggestive of an antiatherogenic activity. ${ }^{61}$ Other experimental investigations were carried out in order to assess, the effect of the administration of grapefruit juice and shaddock on the activity of the Angiotensin-1 Converting Enzyme (ACE) in vitro and on the hypocholesterolemic properties of juices in rats fed a high cholesterol diet. The results from these studies showed that, grapefruit juice had a higher total flavonoid content than shaddock juice, and that both juices inhibited ACE activity in a dose-dependent manner. In addition, the administration of juices to rats fed a high cholesterol diet, resulted in a significant reduction of total cholesterol, triglycerides and LDL-cholesterol levels, and in increase of HDL (High-Density Lipoprotein-cholesterol) plasma levels. ${ }^{62}$ Studies aimed at assessing the effects of quercetin and myricetin on isolated and perfused Wistar rat hearts showed that low concentration of quercetin induced inotropic and lusitropic effects while, myricetin low doses pure induced coronary dilation. On the other hand, the simultaneous administration of these two flavonoids produced only vasodilation. Cardiomodulation induced by the basic mechanical performance of quercetin and the selective vasodilatation induced by myricetin indicate these flavonoids as powerful cardioactive molecules which are able to protect the heart from cardiovascular diseases. ${ }^{63}$

\section{Human studies}

Observational studies carried out to evaluate the effects of daily intake of citrus fruits in humans have shown a beneficial impact of these compounds on human health. For example Mink et al. have highlighted the fact that a daily glass of orange reduces the risk of stroke in men by $25 \%$ while, a dietary intake of grapefruit was associated with a significant reduction in mortality due to coronary heart disease in women. ${ }^{64} \mathrm{~A}$ study performed on employees of an orange juice factory with mild hypercholesterolemia showed that the daily intake of $480 \mathrm{ml}$ of juice was associated with a significant reduction of serum concentration of total cholesterol, LDL cholesterol and apoB. ${ }^{65}$ Furthermore, a study undertaken on 10,623 subjects who took citrus fruit 6 times a week showed an inverse association with cardiovascular events and in particular ischemic stroke. ${ }^{66}$ Studies of Gorinstein et al. have demonstrated that the consumption of citrus fruits reduced the plasma levels of triglycerides in patients with cardiovascular diseases. ${ }^{67}$ Other reports have shown a significant reduction of triglycerides in subjects with hyperlipidemia and hypertriglyceridemia following the daily intake of glucosylhesperidin. ${ }^{68,69}$ Moreover, studies in patients with hypercholesterolemia revealed that a daily intake of naringin $(400 \mathrm{mg} /$ day for 8 weeks) resulted in a $17 \%$ reduction of LDL-C and apoB plasma levels. ${ }^{70}$ Clinical observations by Roza et al. highlighted the fact that subjects with hypercholesterolaemia, receiving $270 \mathrm{mg}$ of citrus flavonoids and $30 \mathrm{mg}$ of palm tocotrienols per day for four-week, had a significant reductions of total cholesterol (20-30\%), low density lipoprotein (19-27\%), triglycerides (24-34\%) and apolipoprotein B (21\%) plasma levels. Furthermore, subjects underwent a longest period of diet (i.e. up to 12 weeks) had an increase in HDL levels (4\%) and a significant increase in apolipoprotein A1 (5\%). ${ }^{71}$ Daily consumption of Sweetie Fruit, a flavanone-rich fruit, administered up to 4-5 weeks has been shown to reduce diastolic blood pressure. ${ }^{72}$ In healthy men, daily consumption of orange juice or hesperidin for 4 weeks significantly improved endothelium-dependent vasodilation starting from six hours after ingestion. ${ }^{73}$ Other clinical investigations undertaken in subjects treated with $500 \mathrm{mg}$ /day of pure hesperidin showed a significant increase in brachial arterymediated flow dilation compared to control subjects. ${ }^{74}$ Citrus flavonoids have been shown to possess also anti-platelet and antiadhesive activity. For instance, methoxylated flavonoids nobiletine and tangeretin, which are much more active than hydroxylated flavonoids showed to have an antiaggregant activity similar to acetylsalicylic acid. ${ }^{75}$ Some authors have pointed out that the inhibition of platelet aggregation depends on the aggregation state of the various chemical structures of several flavonoids. ${ }^{76}$ In this context, in vitro studies have shown that flavonoids, by interacting with platelet membranes, can therefore induce cumulative effects over the time. ${ }^{77}$ On the other hand, platelet aggregation induced by arachidonic acid is more inhibited by fisetin, kaempferol and quercetin than by myricetin. Furthermore, quercetin, fisetin and myricetin showed a more marked inhibitory effect on collagen-induced aggregation. ${ }^{78}$ Alcaraz et al. have shown that flavonoids are antithrombotic factors that act by inhibiting the activity of cyclooxygenase and lipoxygenase, and a consequent reduction of thromboxane $\mathrm{A} 2$ and the production of 4-series leukotrienes. The anti-thrombotic effects exerted by flavonols are the consequence of their binding to platelet mural thrombus. In addition, their ability to eliminate free radicals result in an activation of the biosynthesis and activity of endothelial prostacycline. ${ }^{79}$ Therefore, flavonols stimulate the release of thrombolytic and vasoprotective endothelial mediators. ${ }^{79}$

\section{Citrus flavonoids and cancer}

Cancer is the second leading cause of death worldwide. ${ }^{80} \mathrm{~A}$ growing number of investigations undertaken in the aim to identify natural products endowed with chemo-preventive activity against malignant diseases has, ultimately, led to the development of the conceptual definition of "functional foods" in the prevention of carcinogenesis. $^{81}$ Growing evidence has identified dietary flavonoids as potential chemopreventive and/or anticancer 
agents. ${ }^{82}$ In vitro studies carried out to clarify the mechanisms by which these molecules induce growth inhibitory effects on tumor cells, have shown that their antioxidant properties can likely account for these effects. ${ }^{83}$ For instance, naringin has been reported to exert its antioxidant effects by up-regulating the gene expressions of some antioxidant enzymes such as Superoxide Dismutase (SOD), Catalase, Glutathione Peroxidase (GPx). ${ }^{84}$ Moreover, flavonoids have been shown to prevent DNA damage and carcinogenesis by directly interacting with carcinogens and by inactivating them. ${ }^{85}$ Furthermore, hesperetin and naringenin have been shown to inhibit the tumor promoting effects of 7,12-dimethylbenz [a] anthracene on breast cancer. ${ }^{86}$ Interestingly, citrus flavonoids have been shown to enhance the effects of antitumor drugs through the modulation of some of the molecular mechanisms which foster the onset of tumor cell resistance. ${ }^{87}$ In addition, quercetin has been reported to increase the cytotoxic effects of adriamycin on the multi-drug resistent human breast cancer MCF-7 cells. ${ }^{88}$ Moreover, apigenin, kaempferol and quercetin have been shown to inhibit the proliferation of human breast, prostate and lung cancer cell lines. ${ }^{89}$ While flavonoids inhibit the proliferation of human leukemia, gastric carcinoma and ovarian carcinoma cells. ${ }^{90-92}$

\section{Colon cancer}

Colon cancer is one of the most common cancers in western countries being its incidence increasing even in subjects $<50$ years of age. ${ }^{93}$ Experimental investigations carried out in a mouse colon carcinogenesis model induced by azoxymethane and dextran sodium sulfate showed that mice fed with nobiletin diet had a reduced risk of developing colon carcinoma. ${ }^{94}$ Furthermore, other in vivo studies highlighted the fact that the administration of flavonoids such chrysin, quercetin and nobiletine, azoxymethane-induced colonic preneoplastic lesions in $\mathrm{C} 57 \mathrm{BL} / \mathrm{KsJ}-\mathrm{db} / \mathrm{db}$ mice, reduced the incidence of aberrant cryptic foci which are known to be closely associated with the development colon adenocarcinoma. ${ }^{95}$ Experimental in vivo studies undertaken to assess, the therapeutic effectiveness of a product formulated from the extraction of citrus peels, in a model of colon tumorigenesis induced by oxymethanes, showed that the oral feeding of the extract of mixed citrus peel reduced the number of large, aberrant cryptic foci in the colon tissues of these mice. Citrus peel extract was also observed to decrease iNOS, COX-2, ODC, VEGF and matrix metalloproteinase-9 (MMP-9) protein levels in the colon tissues of mice. ${ }^{96}$ Furthermore, other in vitro studies have shown that apinella and quercetagetin inhibited cell proliferation of human SW480, colon cancer cells and modulate the expression of apoptosis-related genes/proteins. ${ }^{97}$ On the other hand, other experimental studies showed that apigenin reduced the number of aberrant crypt foci and azoxymethane-induced tumor formation in CF-1 mice. ${ }^{98}$ Moreover, diets containing hesperitin have been shown to decrease the number of aberrant crypt foci in Wistar rats treated with 1,2 dimethylhydrazine. ${ }^{99}$ Leonardi et al. investigated the effects of four citrus flavonoids, namely naringenin, apigenin, hesperidine and nobiletine, and a mixture of limonoid (limonin glucoside/obacunone glucoside) on the azoxymethane-induced colon cancer promotion in rats. These studies showed that apigenin lowered the number of aberrant crypt foci compared to rats fed a controlled diet, while naringenin lowered the number of foci and the proliferation index. Both apigenin and naringenin increased apoptosis of the luminal surface colonocytes. On the other hand a glucose mixture of hesperidin, nobiletin and the glucoside/obacunone limonin did not show to exert these effects. ${ }^{100}$ Some clinical investigations have reported that a mixture of apigenin and epigallocatechin gallate suppressed the recurrence of colon cancer in humans under- went surgery. ${ }^{101}$ These findings have provided evidence regarding a possible clinical role of naringenin and apigenin as natural chemo-preventive agents against colon carcinogenesis. ${ }^{102}$

\section{Lung cancer}

Lung cancer is the leading cause of cancer death among men and the second leading cause of cancer death among women worldwide. ${ }^{103}$ The correlation between flavonoid intake and rate of lung cancer risk has been investigated by a food-frequency questionnaire study carried out in a population-based control case study of 1061 cases and 1425 controls. ${ }^{104}$ The results from this study showed a significant correlation between intake of food containing low levels of flavonoids and increased the risk of lung cancer. ${ }^{104} \mathrm{In}$ line with these findings, other case-control study have reported a significant inverse associations between lung cancer risk and the main food sources of flavonoids including quercetin, deriving from the intake of onions and apples and naringin deriving from white grapefruit. ${ }^{105}$ One of the main citrus flavonoids, i.e. nobiletin, has shown to inhibit A549 human lung cancer cell growth in vitro by inducing apoptosis by inhibiting the expression of $\mathrm{Bcl}-2$ protein, and increasing Bax (higher $\mathrm{Bax} / \mathrm{Bcl}-2$ protein ratio) and that of p53, while this compound showed to cause cell cycle arrest at the G2/M phase. ${ }^{106}$

Consistent with these results, Park et al. have recently shown that Korean Citrus aurantium L. has antimetastasis activity. $C$. aurantium L., known as bitter orange, is used as a flavoring and acidifying agent for foods, ${ }^{107}$ the major flavonoids present in these fruits are nobiletin, naringin, and hesperidin, while the most commonly detected free flavones are apigenin, luteolin, and diosmetin. ${ }^{108}$ This study highlighted the fact that flavonoids isolated from C. aurantium were able to prevent the homing and dissemination of A549 human lung adenocarcinoma cells in lung tissues of syngenic mice. ${ }^{108}$ These effects have been attributed to the proapoptotic and anti-migratory effects induced by flavonoids. ${ }^{108}$ These findings further suggest a potential clinical use of flavonoids isolated from $C$. aurantium in the prevention and treatment of human lung cancer. In this setting Bruno et al. carried out some in vitro experiments to investigate the antitumor effects of apigenin on human A549 lung adenocarcinoma cell line. These studies demonstrated that this molecule significantly reduced the rate of cell proliferation and increased the spontaneous release of ROS thus inducing tumor cell death. These data are suggestive for a future complementary therapeutic approach with apigenin in patients with lung adenocarcinoma. ${ }^{109}$

\section{Breast cancer}

Epidemiological studies show an inverse association between increased intake of food flavonoids and the reduced risk of breast cancer. ${ }^{110}$ Flavonoids are endowed with antioxidant activity. Furthermore, their estrogen-like chemical structure allows them to interact with estrogen receptors, thus exerting a phytoestrogen-like activity. ${ }^{111,112}$ These effects, which account also for their modulating activity on endogenous estrogens and their metabolism, has been suggested as possible mechanisms which mediate the antiproliferative properties of these molecules. ${ }^{111,112}$ This hypothesis has been corroborated by the results from in vitro studies showing that hesperetin, naringenin, baicalein, galangin, genistein and quercetin inhibited the proliferation of MDA-MB-435 human breast cancer cells. ${ }^{113}$ Furthermore, hesperetin, naringenin, baicalein, galangine, genistein and quercetin and grapefruit concentrate and orange juice, have been shown to inhibit the proliferation of 7.12-dimethylbenz [a] anthracene (DMBA) induced breast 
tumors in female rats. ${ }^{113}$ In line with these observations, recent findings have reported that the exposure of various breast cancer cell lines to Oncamex, a second-generation flavonoid analogue, reduced cell viability and induced cytotoxicity and apoptosis, concomitant with increased caspase activation. ${ }^{114}$ Furthermore, it has been reported that the polymethoxyflavones of sweet orange peel induced apoptosis in human breast cancer cells (MCF-7), ${ }^{115}$ while hesperetin inhibited the proliferation of MCF-7 breast cancer by causing cell cycle arrest in G1 phase. ${ }^{115}$

\section{Prostate cancer}

Prostate cancer is one of the most common cancers and is the third most common cause of cancer death in men of all ages. ${ }^{116,117}$ Flavonoid-rich diets have been associated with a reduced incidence and mortality of prostate cancer. ${ }^{118}$ The lowest incidence of prostate cancer worldwide has been observed in populations consuming the largest amount of flavonoids. ${ }^{119}$ As many experimental studies highlighted the protective effects of these molecule on prostate cancer, a greater intake of flavonoids through an increased consumption of fruit and vegetables, may be an useful approach in preventing prostate cancer. ${ }^{119}$ Naringenin, has been shown to stimulate DNA repair following oxidative damage in human prostate cancer cells. ${ }^{120}$ On the other hand, hesperidin, has been shown to inhibit the growth of prostate cancer cells by multiple mechanisms, in addition this compound may inhibit testosterone-induced proliferation of prostate cancer cells probably, by interacting with androgen receptors. ${ }^{121}$ Furthermore, nobiletin extracted from a flavonoid mixture decreased the viability of PC3 and DU-145 prostate cancer cell lines. Therefore, these studies suggest a possible clinical role of nobiletin, eventually given in association with other therapeurtic options, to improve the survival rates of prostate cancer patients. ${ }^{122}$ Further, myricetin has been shown to exert inhibitory effects on PC-3 human prostate cancer cell lines. The combination of myricetin and myricitrin resulted in synergic antiproliferative effects on cancer cells, the rate of apoptosis increases in a dose-dependent manner after treatment with flavonoids. ${ }^{123}$ An extract of multiple varieties of citrus peels containing high concentrations of flavonoids, has been shown to suppress the growth of cancer cells in vivo by using a human prostate tumor xenograft mouse model. ${ }^{124}$

\section{Thyroid cancer}

Thyroid cancer is the most common malignant tumor of the endocrine system. Its incidence has increased worldwide. ${ }^{125}$ However, the causes of this phenomenon are still highly debated. In many cases, the normal mechanisms which regulate the Iodine uptake by thyrocites, remail unaltered also differentiated thyroid carcinoma. In this context, the aim of the radioiodometabolic therapy performed after total thyroidectomy, is directed to kill metastatic cancer cells by radioactive iodine picked up by any thyroid residues or malignant tissue. This therapeutic approach, results, in general, in an excellent prognosis for these tumors. ${ }^{126}$ In some cases, due to the down-regulation of the iodine transport protein in the thyrocytes (sodium-iodide symporter-NIS), cancer cells partially lose the ability to concentrate iodine inside the cells, thus making radioiodine therapy less effective. In this setting, some experimental observations have shown that some flavonoids reduced the rate of cell proliferation and increased cell death, as well as increase NIS mRNA levels and iodine absorption. ${ }^{127}$ In line with these findings Allegri et al. have carried out some studies to assess the antitumor activity of resveratrol, genistein, and epigallocatechin-3-gallate on two cell lines derived from anaplas- tic thyroid carcinoma namely, SW1736 and 8505C. These authors demonstrated a decrease in cell viability and an increase of apoptosis in cells of this very aggressive tumor which usually does not respond to radiodometabolic therapy. ${ }^{128}$ Experimental studies on the effects of flavonoids extracted from mandarin juice on the proliferation and migration of CAL-62, C-643 and 8505C human anaplastic thyroid carcinoma cell lines showed that flavonoid components of the tangerine juice extract significantly reduced the proliferation of all these cancer cell lines by blocking them in the G2/M phase of the cell cycle. Furthermore, the extract also caused a reduction of cell migration, which was associated with a reduced expression of matrix-metalloproteinase-2 (MMP-2). ${ }^{129}$ Moreover, another study on an anaplastic thyroid carcinoma cell line (HTh7) showed that hesperedine was effective in reducing cell proliferation and survival mainly by inducing apoptosis. On the other hand, hesperetin also induced cellular re-differentiation of anaplatic thyroid cancer. ${ }^{130}$

\section{Discussion}

The studies reported in the present review indicate that flavonoids appear to be useful functional food compounds, in the prevention of some chronic pathological conditions. ${ }^{131,132}$ In particular, experimental in vitro and in vivo investigations indicate that citrus flavonoids may play an important role in the prevention and treatment of atherosclerosis and human tumors. ${ }^{133,134,135}$ Besides vitamin $\mathrm{C}$, folate, dietary fiber and carotenoids, ${ }^{136}$ the beneficial effects of diet citrus fruits can be attributed, in particular, to the antioxidant activity of flavonoids present in this fruit. The studies on the therapeutic effects of flavonoids is complex due to the heterogeneity of various molecules. Cardiovascular diseases and cancers are pathological conditions associated with the highest incidence and mortality worldwide. ${ }^{137}$ On the other hand, multiple environmental and/or genetic factors have been shown to contribute to these increasing incidence of these non communicable diseases. In these recent years, balanced diets have gained a significant attention with regard to the clinical treatment of atherosclerosis, cardiovascular diseases and tumors. The use of citrus fruits in the daily diet not only provides important nutrients such as vitamins, mineral salts, trace elements but also numerous functional molecules that are useful to maintain normal body's homeostasis. In particular flavonoids present in citrus fruits possess antioxidant, anti-inflammatory, hypolipidemic, antidiabetic and anticancer effects. These observations suggest that, citrus flavonoids may be of clinical relevance in the prevention and treatment of atherosclerosis and human tumors. Current dietary recommendations are based on the advice to consume fruits, vegetables and drinks, such as red wine, containing flavonoids on daily bases. However, current efforts are directed to find out most suitable molecules and/or novel, effective associations among multiple flavonoid molecules that can result in an improved therapeutic activity. On the other hand, further investigations are needed to better assess the pharmacokinetics pathways of these molecules following their long-term daily intake. The role of citrus flavonoids on human health currently is an a growing area of research interest. The advances in the technologies used for improving the separation and purificationof flavonoids will contribute to better define the biological activity of these compounds. Further investigations may better assess the pharmacokinetics pathways of these molecules following their long-term daily intake. 


\section{References}

1. Adefegha SA. Functional foods and nutraceuticals as dietary intervention in chronic diseases; novel perspectives for health promotion and disease prevention. J Diet Suppl 2018;15:9771009.

2. Gentile D, Fornai M, Pellegrini C, et al. Dietary flavonoids as a potential intervention to improve redox balance in obesity and related comorbidities: a review. Nutr Res Rev 2018;31:239-47.

3. Dillard CJ, German JB. Phytochemicals: nutraceuticals and human health. J Sci Food Agric 2000;80:1744-56.

4. Keys A. Mediterranean diet and public health: Personal reflections. Am J Clin Nutr 1995;61:1321-3.

5. Casas R, Sacanella E, Estruch R. The immune protective effect of the Mediterranean diet against chronic low grade inflammatory diseases. Endocr Metab Immune Disord Drug Targets 2016;14:245-54.

6. Tripoli E, La Guardia M, Giammanco S, et al. Citrus flavonoids: molecular structure, biological activity and nutritional properties: A review. Food Chem 2007;104:466-79.

7. Heim KE, Tagliaferro AR, Bobilya DJ. Flavonoid antioxidants: chemistry, metabolism and structure-activity relationships. J Nutr Biochem 2002;13:572-84.

8. Mulvihill EE, Burke AC, Huff MW. Citrus flavonoids as regulators of lipoprotein metabo-lism and atherosclerosis. Annu Rev Nutr 2016;36:275-99.

9. Rodríguez-García C, Sánchez-Quesada C, Gaforio JJ. Dietary flavonoids as cancer chemo-preventive agents: an updated review of human studies. Antioxidants 2019;8:137.

10. $\mathrm{Xu} \mathrm{H}$, Luo J, Huang J, Wen Q. Flavonoids intake and risk of type 2 diabetes mellitus. A meta-analysis of prospective cohort studies. Medicine 2018;97:e0686.

11. Hwang SL, Shih PH, Yen GC. Neuroprotective effects of citrus flavonoids. J Agric Food Chem 2012;60:877-85.

12. Hardcastle AC, Aucott L, Reid DM, Macdonald HM. Associations between dietary flavonoid intakes and bone health in a Scottish population. J Bone Miner Res 2011;26:941-7.

13. Cassidy A, Rimm EB, O'Reilly EJ, et al. Dietary flavonoids and risk of stroke in women. Stroke 2012;43:946-51.

14. Di Majo D, La Guardia M, Leto G, et al. Flavonols and flavan-3-ols as modulators of xanthine oxidase and manganese superoxide dismutase activity. Int $\mathrm{J}$ Food Sci Nutr 2014;65:886-89.

15. Panche AN, Diwan AD, Chandra SR. Flavonoids: an overview. J Nutr Sci 2016;5:1-15.

16. Croft KD. The chemistry and biological effects of flavonoids and phenolic acids. Ann NY Acad Sci 1998;854:435-42.

17. Yusof S, Ghazali HM, King GS. Naringin content in local citrus fruits. Food Chem 1990;37:113-12.

18. Horowitz RM. Taste effects of flavonoids. Prog Clin Biol Res 1986;213:163-75.

19. Caristi C, Bellocco E, Gargiulli C, et al. Flavone-di-C-glycosides in citrus juices from Southern Italy. Food Chem 2006;95:431-437.

20. Tsiokanos E, Tsafantakis N, Termentzi A, et al. Phytochemical characteristics of bergamot oranges from the Ionian islands of Greece: A multianalytical approach with emphasis in the distribution of neohesperidose flavanones. Food Chem 2021;343:128400

21. Ooghe WC, Detavernier CM. Detection of the addition of
Citrus reticulata and hybrids to Citrus sinensis by flavonoids. J Agric Food Chem 1997;45:1633-7.

22. Narayana KR, Reddy MS, Chaluvadi MR, Krishna DR. Bioflavonoids classification, pharmacological, biochemical effects and therapeutic potential. Indian $\mathrm{J}$ Pharmacol 2001;33:2-16.

23. Verma ML, Sharma S, Saini R, et al. Chapter 3Bioflavonoids: Synthesis, functions and biotechnological applications. Biotechnological Product Bioact Comp 2020;2020:69-105.

24. Kumar S, Pandey AK. Chemistry and biological activities of flavonoids: an overview. Scient World J 2013;2013:162750.

25. Tripoli E, La Guardia M, Giammanco S, et al. Citrus flavonoids: molecular structure, biological activity and nutritional properties: A review. Food Chem 2007;104:466-79.

26. Feng X, Li Y, Brobbey M, et al. Insights into the intestinal bacterial metabolism of flavonoids and the bioactivities of their microbe derived ring cleavage metabolites. Drug Metab Rev 2018;50:343-56.

27. Nielsen IL, Chee WS, Poulsen L, et al. Bioavailability is improved by enzymatic modification of the citrus flavonoid hesperidin in humans: a randomized, double-blind, crossover trial. J Nutr 2006;136:404-8.

28. Kanaze FI, Bounartzi MI, Georgarakis M, Niopas, I. Pharmacokinetics of the citrus flavanone aglycones hesperetin and naringenin after single oral administration in human subjects. Eur J Clin Nutr 2007;61:472-77.

29. Lin SP, Hou YC, Tsai SY, et al. Tissue distribution of naringenin conjugated metabolites following repeated dosing of naringin to rats. Biomedicine 2014;4:16.

30. Ekalu A, Habila JH. Flavonoids: isolation, characterization, and health benefits. Beni Suef Univ J Basic Appl Sci 2020;9:45.

31. Burda S, Oleszek W. Antioxidant and antiradical activities of flavonoids. J Agric Food Chem 2001;49:2774-9.

32. Di Majo D, Giammanco M, La Guardia M, et al. Flavanones in citrus fruit: structure antioxidant activity relationships. Food Res Int 2005;38:1161-6.

33. Benavente-García O, Castillo J. Update on uses and properties of Citrus flavonoids: new findings in anticancer, cardiovascular, and antiinflammatory activity. J Agric Food Chem 2008;56:6185-6205.

34. Sichel G, Corsaro C, Scalia M, et al. In vitro scavenger activity of some flavonoids and melanins against $\mathrm{O} 2 \bullet$-. Free Radic Biol Med 1991;11:1-8.

35. Di Majo D, La Neve L, La Guardia M, et al. The influence of two different $\mathrm{pH}$ levels on the antioxidant properties of flavonols, flavan-3-ols, phenolic acids and aldehyde compounds analysed in synthetic wine and in a phosphate buffer. J Food Compost Anal 2011;24:265-9.

36. Cillard J, Cillard P. Composes phenoliques et radicaux libres. STP Pharma 1988;4:592-6.

37. Rapisarda P, Tomaino A, Lo Cascio R, et al. Effec-tiveness as influenced by phenolic content of fresh orange juices. J Agric Food Chem 1999;47:4718-23.

38. Di Majo D, La Guardia M, Crescimanno M, et al. In-fluence of flavonoids on the transmembrane electron transport: study ex vivo. 2015;88:59-60.

39. Di Majo D, La Guardia M, Di Sclafani E, et al. Influence of quercetin and luteolin on the activity of the catalase: Study ex vivo about erythrocytes in smokers and non-smokers. J Biol Res 2015;88:61-2.

40. Maleki SJ, Crespo JF, Cabanillas B. Anti-inflammatory effects of flavonoids. Food Chem 2019;299:124-5. 
41. Rathee P, Chaudhary H, Rathee S, et al. Mechanism of action of flavonoids as anti-inflammatory agents: a review. Inflamm. Allergy Drug Targets 2009, 8, 229-235. 10.2174/ 187152809788681029

42. Manthey JA, Guthrie N, Grohmann K. Biological properties of citrus flavonoids pertaining to cancer and inflammation. Curr Med Chem 2001;8:135-53.

43. Da Silva EJA, Oliveira AS, Lapa AJ. Pharmacological evaluation of the antiinflammatory activity of a citrus bioflavonoid, hesperidin, and the isoflavonoids, duartin and claussequinone, in rats and mice. J Pharm Pharmacol 1994;46:118-22.

44. Sakata K, Hirose Y, Qiao Z, et al. Inhibition of inducible isoforms of cyclooxygenase and nitric oxide synthase by flavonoid hesperidin in mouse macrophage cell line. Cancer Lett 2003;199:139-45.

45. Lin N, Sato T, Takayama Y, et al. Novel anti inflammatory actions of nobiletin, a citrus polymethoxy flavonoid, on human synovial fibroblasts and mouse macrophages. Biochem Pharmacol 2003;65:2065-71.

46. Huxley RR, Neil HAW. The relation between dietary flavonol intake and coronary heart disease mortality: a meta-analysis of prospective cohort studies. Eur J Clin Nutr 2003;57:904-8.

47. Alam MA, Subhan N, Rahman MM, et al. Effect of citrus flavonoids, naringin and naringenin, on metabolic syndrome and their mechanisms of action. Adv Nutr 2014;5: 404-17.

48. Fuhrman B, Aviram M. Flavonoids protect LDL from oxidation and attenuate atherosclerosis. Curr Opin Lipidol 2001;12:41-8.

49. Naderi GA, Asgary S, Sarraf-Zadegan GN, Shirvany H. Antioxidant effect of flavonoids on the susceptibility of LDL oxidation. Mol Cell Biochem 2003;246:193-6.

50. Mahmoud AM, Hernández Bautista RJ, Mansur A, et al. Beneficial effects of citrus flavonoids on cardiovascular and metabolic health. Oxid Med Cell Longev 2019;19:5484138.

51. Kurowska EM, Borradaile NM, Spence JD, Carroll KK. Hypocholesterolemic effects of dietary citrus juices in rabbits. Nutr Res 2000;20:121-9.

52. Kim HK, Jeong TS, Lee MK, et al. Lipid lowering efficacy of hesperetin metabolites in high-cholesterol fed rats. Clin Chim Acta 2003;327:129-37.

53. Chtourou Y, Fetoui H, Jemai R, et al. Naringenin reduces cholesterol induced hepatic inflammation in rats by modulating matrix metalloproteinases-2, 9 via inhibition of nuclear factor кB pathway. Eur J Pharmacol 2015;746:96-105.

54. Kurowska EM, Manthey JA. Hypolipidemic effects and absorption of citrus polymethoxylated flavones in hamsters with diet induced hypercholesterolemia. J Agric Food Chem 2004;52:2879-86.

55. Park HJ, Jung UJ, Cho SJ, et al. Citrus unshiu peel extract ameliorates hyperglycemia and hepatic steatosis by altering inflammation and hepatic glucose- and lipid-regulating enzymes in db/db mice. J Nutr Biochem 2013;24:419-27.

56. Lee S, Park YB, Bae KH, et al. Cholesterol lowering activity of naringenin via inhibition of 3- hydroxy-3-methylglutaryl coenzyme A reductase and acyl coenzyme A: cholesterol acyltransferase in rats. Ann Nutr Metab 1999;43:173-80.

57. Lee MK, Moon SS, Lee SE, et al. Naringenin 7-O-cetyl ether as inhibitor of HMG-CoA reductase and modulator of plasma and hepatic lipids in high cholesterol-fed rats. Bioorg Med Chem 2003;11:393-8.

58. Chanet A, Milenkovic D, Deval C, et al. Naringin, the major grapefruit flavonoid, specifically affects atherosclerosis development in diet-induced hypercholesterolemia in mice. J Nutr Biochem 2012;23:469-77.

59. Lee $\mathrm{CH}$, Jeong TS, Choi YK, et al. Anti-atherogenic effect of citrus flavonoids, naringin and naringenin, associated with hepatic ACAT and aortic VCAM-1 and MCP-1 in high cholesterol-fed rabbits. Biochem. Biophys Res Commun 2001;284: 681-88.

60. Lee S, Lee $\mathrm{CH}$, Moon SS, et al. Naringenin derivatives as antiatherogenic agents. Bioorg Med Chem Lett 2003;13:3901-3.

61. Mulvihill EE, Assini JM, Sutherland BG, et al. Naringenin decreases progression of atherosclerosis by improving dyslipidemia in high fat-fed low density lipoprotein receptor-null mice. Arterioscler Thromb Vasc Biol 2010;30:742-8.

62. Oboh G, Bello FO, Ademosun AO. Hypocholesterolemic properties of grapefruit (Citrus paradisii) and shaddock (Citrus maxima) juices and inhibition of angiotensin-1-converting enzyme activity. J Food Drug Anal 2014;22:477-84.

63. Angelone T, Pasqua T, Di Majo D, et al. Distinct signalling mechanisms are involved in the dissimilar myocardial and coronary effects elicited by quercetin and myricetin, two red wine flavonols. Nutr Metab Cardiovasc Dis 2011;21:362-71.

64. Mink PJ, Scrafford CG, Barraj LM, et al. Flavonoid intake and cardiovascular disease mortality: a prospective study in postmenopausal women. Am J Clin Nutr 2007;85;895-909.

65. Aptekmann NP, Cesar TB. Long-term orange juice consumption is associated with low LDL-cholesterol and apolipoprotein $\mathrm{B}$ in normal and moderately hypercholesterolemic subjects. Lipids Health Dis 2013;12:119.

66. Yamada T, Hayasaka S, Shibata Y, et al. Frequency of citrus fruit intake is associated with the incidence of cardiovascular disease: the Jichi Medical School cohort study. J Epidemiol 2011;21:169-75.

67. Gorinstein S, Caspi A, Libman I, et al. Red grapefruit positively influences serum triglyceride level in patients suffering from coronary atherosclerosis: studies in vitro and in humans. J Agr Food Chem 2006;54:1887-92.

68. Miwa Y, Yamada M, Sunayama T, et al. Effects of glucosyl hesperidin on serum lipids in hyperlipidemic subjects: preferential reduction in elevated serum triglyceride level. J Nutr Sci Vitaminol 2004;50:211-8.

69. Miwa Y, Mitsuzumi H, Sunayama T, et al. Glucosyl hesperidin lowers serum triglyceride level in hypertriglyceridemic subjects through the improvement of very low density lipoprotein metabolic abnormality. J Nutr Sci Vitaminol 2005;51:460-70.

70. Jung UJ, Kim HJ, Lee JS, et al. Naringin supplementation lowers plasma lipids and enhances erythrocyte antioxidant enzyme activities in hypercholesterolemic subjects. Clin Nutr 2003;22:561-8.

71. Roza JM, Xian-Liu Z, Guthrie N. Effect of citrus flavonoids and tocotrienols on serum cholesterol levels in hypercholesterolemic subjects. Altern Ther Health Med 2007;13:44-8.

72. Reshef N, Hayari Y, Goren C, et al. Antihypertensive effect of sweetie fruit in patients with stage I hypertension. Am J Hypertens 2005;8:1360-63.

73. Morand C, Dubray C, Milenkovic D, et al. Hesperidin contributes to the vascular protective effects of orange juice: a randomized crossover study in healthy volunteers. Am J Clin Nutr 2011:93;73-80.

74. Rizza S, Muniyappa R, Iantorno M, et al. Citrus polyphenol hesperidin stimulates production of nitric oxide in endothelial cells while improving endothelial function and reducing inflammatory markers in patients with metabolic syndrome. J Clin Endocrinol Metab 2011;96:782-92. 
75. Benavente-Garcìa $\mathrm{O}$, Castillo J, Marin FR, et al. Uses and properties of citrus flavonoids. J Agric Food Chem 1997;45:4505-15.

76. Manach C, Regerat F, Texier O, et al. Bioavailability, metabolism and physiological impact of 4-oxo-flavonoids. Nutr Res 1996;16:517-44.

77. Van Wauwe J, Goossens J. Effects of antioxidants on cyclooxygenase and lipoxygenase activities in intact human platelets: Comparison with indomethacin and ETYA. Prostaglandins 1983;26:725-30.

78. Tzeng SH, Ko WC, Ko FN, Teng CM. Inhibition of platelet aggregation by some flavonoids. Thromb Res 1991;64:91-100.

79. Alcaraz MJ, Ferrandiz ML. Modification of arachidonic metabolism by flavonoids. J Ethnopharmacol 1987;21:209-29.

80. Reyes-Farias M, Carrasco-Pozo C. The anticancer effect of quercetin: Molecular implications in cancer metabolism. Int J Mol Sci 2019;20:3177.

81. Aghajanpour M, Nazer MR, Obeidavi Z, et al. Functional foods and their role in cancer prevention and health promotion: a comprehensive review. Am J Cancer Res 2017;7:740-69.

82. Rawson NE, Ho CT, Li S. Efficacious anticancer property of flavonoids from citrus peels. Food Sci Human Wellness 2014;3:104-9.

83. Shimoi K, Masuda S, Furogori M, et al. Radioprotective affect of antioxidative flavonoids in c-ray irradiated mice. Carcinogenesis 1994;15:2669-72.

84. Jeon SM, Bok SH, Jang MK, et al. Antioxidative activity of naringin and lovastatin in high cholesterol-fed rabbits. Life Sci 2001;69:2855-66.

85. Heo HY, Lee SJ, Kwon CH, et al. Anticlastogenic effects of galangin against bleomycin-induced chromosomal aberrations in mouse spleen lymphocytes. Mut Res 1994;311:225-9.

86. So FV, Guthrie N, Chambers AF, et al. Inhibition of human breast cancer cell proliferation and delay of mammary tumorigenesis by flavonoids and citrus juices. Nutr Cancer 1996;26:167-81.

87. Wesołowska O, Wisniewski J, Roda-Pomianek KS, et al. Multidrug resistance reversal and apoptosis induction in human colon cancer cells by some flavonoids present in citrus plants. J Nat Prod 2012;75:1896-902.

88. Scambia G, Ranelletti FO, Benedetti-Panici P, et al. Quercetin potentiates the effect of adriamycin in a multidrug resistant MCF-7 human breast cancer cell line: P-glycoprotein as a possible target. Cancer Chemother Pharmacol 1994;34:459-64.

89. Manthey JA, Guthrie N. Antiproliferative activities of citrus flavonoids against six human cancer cell lines. J Agric Food Chem 2002;50:5837-43.

90. Larocca LM, Piantelli M, Leone G, et al. Type II oestrogen binding sites in acute lymphoid and myeloid leukaemias: Growth inhibitory effect of oestrogen and flavonoids. Br J Haematol 1990;75:489-95.

91. Yoshida M, Sakai T, Hosokawa N, et al. The effect of quercetin on cell cycle progression and growth of human gastric cancer cells. FEBS Lett 1990;260:10-3.

92. Scambia G, Ranelletti FO, Benedetti-Panici P, et al. Inhibitory effect of quercetin on OVCA 433 cells and presence of type II oestrogen binding sites in primary ovariun tumors and cultured cells. Br J Cancer 1990;62:942-6.

93. Feletto E, Yu XQ, Lew JB, et al. Trends in colon and rectal cancer incidence in Australia from 1982 to 2014: Analysis of data on over 375,000 cases. Cancer Epidemiol Biomarkers Prev 2019;28:83-90.

94. Miyamoto S, Yasui Y, Tanaka T, et al. Suppressive effects of nobiletinon hyperleptinemia and colitis related colon carcinogenesis in male iCR mice. Carcinogenesis 2008;29:1057-63.

95. Miyamoto S, Yasui Y, Ohigashi H, et al. Dietary flavonoids suppress azoxymethane-induced colonic preneoplastic lesions inmale C57BL/KsJ-db/db mice. Chem Biol Interact 2010;183: 276-83.

96. Lai CS, Li S, Liu CB, et al. Effective suppression of azoxymethane induced aberrant crypt foci formation in mice with citrus peel flavonoids. Mol Nutr Food Res 2013;57:551-5.

97. Murthy KNC, Kim J, Vikram A, Patil BS. Differential inhibition of human colon cancer cells by structurally similar flavonoids of citrus. Food Chem 2012;132:27-34.

98. Au A, Li B, Wang W, et al. Effect of dietary apigenin on colonic ornithine decarboxylase activity, aberrant crypt foci formation, and tumorigenesis in different experimental models. Nutr Cancer 2006;54:243-51.

99. Aranganathan S, Selvam JP, Nalini N. Effect of hesperetin, a citrus flavonoid, on bacterial enzymes and carcinogen-induced aberrant crypt foci in colon cancer rats: a dose dependent study. J Pharm Pharmacol 2008;60:1385-92.

100. Leonardi T, Vanamala J, Taddeo SS, et al. Apigenin and naringenin suppress colon carcinogenesis through the aberrant crypt stage in azoxymethane-treated rats. Exp Biol Med 2010;235:710-7.

101. Hoensch H, Groh B, Edler L, Kirch W. Prospective cohort comparison of flavonoid treatment in patients with resected colorectal cancer to prevent recurrence. World J Gastroenterol 2008; 14:2187-93.

102. Jaganathan SK, Vellayappan MV, Narasimhan G, Supriyanto E. Role of pomegranate and citrus fruit juices in colon cancer prevention. World J Gastroenterol 2014;20:4618-25.

103. Torre LA, Siegel RL, Jemal A. Lung cancer statistics. In: Lung Cancer and Personalized Medicine. Adv Exp Med Biol 2016;893:1-19.

104. Christensen KY, Naidu A, Parent ME, et al. The risk of lung cancer related to dietary intake of flavonoide. Nutr Cancer 2012;64:964-74.

105. Le Marchand L, Murphy SP, Hankin JH, et al. Intake of Flavonoids and Lung Cancer. J Natl Cancer Inst 2000;92:154-60.

106. Luo G, Guan X, Zhou L. Apoptotic effect of citrus fruit extract nobiletin on lung cancer cell line A549 in vitro and in vivo. Cancer Biol Ther 2008;7:966-73.

107. Park KI, Park HS, Kim MK, et al. Flavonoids identified from Korean Citrus aurantium L. inhibit non small cell lung cancer growth in vivo and in vitro. J Funct Foods 2014;7:287-29.

108. Suntar I, Khan H, Patel S, Celano R, Rastrelli L. An Overview on Citrus aurantium L.: Its Functions as Food Ingredient and Therapeutic Agent. Oxid. Med. Cell. Longev. 2018, 2018, 7864269.

109. Bruno A, Siena L, Gerbino S, et al. Apigenin affects leptin/leptin receptor pathway and induces cell apoptosis in lung adenocarcinoma cell line. Eur J Cancer 2011;47:2042-51.

110. Sak K. Epidemiological evidences on dietary flavonoids and breast cancer Risk: A narrative review. Asian Pac J Cancer Prev 2017;18:2309-28.

111. Hitomi T, Hiroyuki S, Shunsuke Y, Kayoko S. Breast cancer and flavonoids - A role in prevention. Curr Pharm Des 2013;19:6125-32.

112. La Guardia M, Giammanco M. Breast cancer and obesity. Panminerva Med 2001;43:123-33.

113. So FV, Guthrie N, Chambers AF, et al. Inhibition of human breast cancer cell proliferation and delay of mammary tumori- 
genesis by flavonoids and citrus juices. Nutr Cancer 1996;26:167-81.

114. Martinez-Perez C, Ward C, Turnbull AK, et al. Antitumour activity of the novel flavonoid Oncamex in preclinical breast cancer models. Br J Cancer 2016;114:905-16.

115. Sergeev IN, Ho CT, Li S, et al. Apoptosis inducing activity of hydroxylated polymethoxyflavones and polymethoxyflavones from orange peel in human breast cancer cells. Mol Nutr Food Res 2007;51:1478-84.

116. Bray F, Ferlay J, Soerjomataram I, et al. Global cancer statistics 2018: GLOBOCAN estimates of incidence and mortality worldwide for 36 cancers in 185 countries. CA Cancer J Clin 2018;68:394-424.

117. Sepporta MV, Tumminello FM, Flandina C, et al. Follistatin as potential therapeutic target in prostate cancer. Targ Oncol 2013;8:215-22.

118. Wang Y, Stevens VL, Shah R, et al. Dietary flavonoid and proanthocyanidin intakes and prostate cancer risk in a prospective cohort of US men. Am J Epidemiol 2014;179:974-86.

119. Haddad AQ, Venkateswaran V, Viswanathan L, et al. Novel antiproliferative flavonoids induce cell cycle arrest in human prostate cancer cell lines. Prostate Cancer P D 2006;9:68-76.

120. Gao K, Henning SM, Niu Y, et al. The citrus flavonoid naringenin stimulates DNA repair in prostate cancer cells. J Nutr Biochem 2006;17:89-95.

121. Lee CJ, Wilson L, Jordan MA, et al. Hesperidin suppressed proliferations of both Human breast cancer and androgen-dependent prostate cancer cells. Phytother Res 2010;24:15-9.

122. Chen JA, Creed A, Chen AY, et al. Nobiletin suppresses cell viability through AKT Pathways in PC-3 and DU-145 prostate cancer cells. BMC Pharmacol Toxicol 2014;15:59.

123. Xu R, Zhang Y, Ye X, et al. Inhibition effects and induction of apoptosis of flavonoids on the prostate cancer cell line PC-3 in vitro. Food Chem 2013;138:48-53.

124. Lai CS, Li S, Miyauchi Y, et al. Potent anticancer effects of citrus peel flavonoids in human prostate xenograft tumors. Food Funct 2013;4:944-9.

125. Pellegriti G, Frasca F, Regalbuto C, et al. Worldwide increas- ing incidence of thyroid cancer: Update on epidemiology and risk factors. J Cancer Epidemiol 2013;10:965212.

126. Giammanco M, Di Gesù G, Massenti MF, et al. Role of color flow Doppler sonography in pre-operative diagnostics of the thyroid pathology. Minerva Endocrinol 2002;27:1-10.

127. Gonçalves CFL, de Freitas ML, Ferreira ACF. Flavonoids, thyroid iodide uptake and thyroid cancer-a review. Int J Mol Sci 2017; 18:1247.

128. Allegri L, Rosignolo F, Mio C, et al. Effects of nutraceuticals on anaplastic thyroid cancercells. J Cancer Res Clin Oncol 2018;144:285-94.

129. Celano M, Maggisano V, De Rose F, et al. Flavonoid fraction of Citrus Reticulata juice reduces proliferation and migration of anaplastic thyroid carcinoma cells. Nutr Cancer 2015;67:1183-90.

130. Patel PN, Yu XM, Jaskula-Sztul R, Chen H. Hesperetin activates the Notch1 signaling cascade, causes apoptosis, and induces cellular differentiation in anaplastic thyroid cancer. Ann Surg Oncol 2014;21:497-504.

131. Ciumărnean L, Milaciu MV, Runcan $\mathrm{O}$, et al. The effects of flavonoids in cardiovascular diseases. Molecules 2020;25:4320.

132. Lafuente AG, Guillamón E, Villares A, et al. Flavonoids as antiinflammatory agents: implications in cancer and cardiovascular disease. Inflamm Res 2009;58:537-552.

133. Salvamani S, Gunasekaran B, Shaharuddin NA, et al. Antiartherosclerotic effects of plant flavonoids. Bio Med Res Int 2014;11:480258.

134. Park EJ, Pezzuto JM. Flavonoids in cancer prevention. Ant Cancer Agent 2012;12:836-51.

135. Scarpa ES, Giammanco M, Magnani M. Gastrointestinal tumors: phytochemical and drug combinations targeting the hallmarks of cancer. Appl Sci 2021;11:10077.

136. Cantarella CD, Ragusa D, Giammanco M, Tosi S. Folate deficiency as predisposing factor for childhood leukaemia: a review of the literature. Genes Nutr 2017;12:14.

137. Araujo F, Gouvinhas C, Fontes F, et al. Trends in cardiovascular diseases and cancer mortality in 45 countries from five continents (1980-2010). Eur J Prev Cardiol 2014;21:1004-17. 